\title{
Enhanced external counterpulsation in rehabilitation of erectile dysfunction: a narrative literature review
}

This article was published in the following Dove Press journal:

Vascular Health and Risk Management

\author{
Seyed Ahmad Raeissadat' \\ Atefeh Javadi ${ }^{2}$ \\ Farzad Allameh ${ }^{3}$ \\ 'Development Research Center of \\ Shahid Modarres Hospital, Physical \\ Medicine and Rehabilitation Research \\ Center, Shahid Beheshti University \\ of Medical Sciences, Tehran, Iran; \\ ${ }^{2}$ Physical Medicine and Rehabilitation \\ Research Center and Department, \\ Shohada-e-Tajrish Hospital, Shahid \\ Beheshti University of Medical \\ Sciences, Tehran, Iran; ${ }^{3}$ Urology and \\ Nephrology Research Center, Shahid \\ Beheshti University of Medical \\ Sciences, Tehran, Iran
}

Background: Enhanced external counterpulsation (EECP) is a noninvasive treatment option widely applied in patients with erectile dysfunction (ED). The aim of this study is to review the efficacy of EECP in patients suffering from ED.

Methods: PubMed, MEDLINE, Google Scholar, Tripdatabase, Scopus, and Cochrane library databases were searched for articles with the following search terms: enhanced external counterpulsation and erectile dysfunction. No restrictions with respect to study setting, date of publication, and language were imposed.

Results: From an initial set of 208 records, 4 studies were selected after a final review. A total of 177 patients with a mean age of 59.98 years were included in these studies, with 20-35 hours per week of EECP treatment. Three studies used the International Index of Erectile Function questionnaire and one applied a four-item questionnaire and a peak systolic flow measurement. All of these parameters were significantly improved after the EECP treatment.

Conclusion: To the best of our knowledge, this is the first study reviewing the clinical effectiveness of EECP in patients with ED. According to the articles reviewed in this study, an improvement in erectile function after EECP treatment courses has been observed in patients with and without coronary artery disease without any significant adverse effects.

Keywords: coronary artery disease, enhanced external counter pulsation, erectile dysfunction, impotence, ischemic heart disease

\section{Introduction}

Erectile dysfunction (ED) is defined as "the inability to attain and/or maintain penile erection sufficient for satisfactory sexual intercourse". ${ }^{1}$

The prevalence of ED has been reported from $19.2 \%$ in Germany ${ }^{2}$ to $52 \%$ in the USA. ${ }^{3}$ It is also very common in the countries in the Arab region, with a reported prevalence rate of $>40 \% .{ }^{4}$ In Iran, ED has been reported to be frequent with a prevalence of $56.1 \% .^{5}$ It is estimated that about half of men aging $>40$ years have some degree of ED. While in 1995, ED affected over 152 million males worldwide, it is expected that in $2025,>320$ million patients will be afflicted. ${ }^{6,7}$

The negative influence of ED on quality of life (QOL) is of specific concern because the inability to have an acceptable sexual relationship can decrease the individual's confidence and lead to psychological disorders and marital tension. It is reported that QOL in patients with ED is $10 \%$ less than in the general population. ${ }^{89}$ According to the increased lifespan and improving general health of the elderly, sexual function becomes a vital aspect of the overall QOL of today's old population. ${ }^{10}$
Correspondence: Farzad Allameh Urology and Nephrology Research Center, Shahid Beheshti University of Medical Sciences, No 103, 9th Boustan, Pasdaran Ave., Tehran I666663III, IR, Iran

$\mathrm{Tel} / \mathrm{Fax}+98$ 2I 22567222

Email farzadallame@gmail.com 
ED has many causes including vascular problems, neurological dysfunction, psychological disorders, comorbidities, ${ }^{11}$ and drug side effects. The prevalence of ED is high among men $>60$ years who have experienced heart attacks. ${ }^{10}$ Recently, more consideration has been given to the correlation between $\mathrm{ED}$ and ischemic heart disease (IHD); therefore, there are more studies showing a major association between these two conditions. ${ }^{12-14}$ In patients with ED, the prevalence of IHD has varied from $5 \%$ to $56 \%$, while in symptomatic patients with IHD, the prevalence of ED has been $44 \%-65 \% .{ }^{13-15} \mathrm{~A}$ generalized atherosclerotic process with endothelial dysfunction in the arterial branches, leading to decreased blood flow, is the underlying mechanism for both ED and coronary artery disease (CAD) ${ }^{16,17}$ Since atherosclerosis is a major pathogenesis of IHD, there is a high probability for ED patients to have IHD due to the atherosclerotic process involving penile vessels. ${ }^{13,18,19}$ It has been suggested that fewer arteries of the penis (diameter 1-2 mm) undergo block due to plaque earlier than the greater coronary (3-4 mm), carotid (5-7 mm), and iliofemoral (6-8 $\mathrm{mm}$ ) arteries; therefore, ED may become symptomatic before coronary events. Similar principal risk factors for both ED and IHD have been reported; ie, aging, hypertension, diabetes, smoking, and dyslipidemia. ${ }^{12,20,21}$ In this regard, an increased number of patients with ED and IHD are expected due to the rise in life expectancy. There are also findings suggesting that higher levels of serum uric acid and lipoprotein-a are associated with the existence of $\mathrm{ED}$ among patients with $\mathrm{CAD}{ }^{22}$

In an evidence-based consensus about the association of ED and CAD, Jackson et $\mathrm{a}^{23}$ reported that CAD develops 2-3 years after the onset of ED. Therefore, there is a need for an additional connection between the ED and cardiovascular investigation fields such as treatment options for both conditions.

The main treatment options for ED are oral drugs (yohimbine, phosphodiesterase [PDE] type 5 inhibitors, etc.) and also drugs for intracavernous or intraurethral administration with other alternative options for treatment such as mechanical or surgical options (vacuum erection devices [VED], penile prosthesis, venous leakage surgery, and arterial reconstruction)..$^{24,25}$

Sildenafil was the first PDE type 5 inhibitor with a treatment effect on $>20$ million males. Patients tolerate sildenafil differently, according to existing comorbidities with more adverse effects in men with IHD and hypertension. The most common adverse events in this regard are headache, flushing, heartburn, vertigo, rhinitis, and visual disturbance. ${ }^{25}$

Intracavernous pharmacotherapy is considered as a second-line treatment for males not responding to oral medications with a high rate of discontinuation and inadequate patient compliance. ${ }^{25}$ Complications such as penile pain, prolonged erections, priapism, and fibrosis have been reported. ${ }^{26}$
There are also problems and adverse effects in using mechanical or surgical treatments such as pain or lack of ability for ejaculation using vacuum constriction devices and infection or mechanical failure after using penile prostheses, regardless of having the effective role for intercourse. ${ }^{27,28}$

A noninvasive management alternative, which has been useful in patients with $E D,{ }^{11,16,29}$ is enhanced external counterpulsation (EECP). This method is based on using a circulatory support device that can improve blood flow in the peripheral and coronary arterial diseases. ${ }^{29}$

EECP was first presented by Zheng et $\mathrm{al}^{30}$ in 1983 who used serial cuff inflation by the replacement of the previous hydraulic system with a pneumatic one. The counterpulsation was synchronized with the cardiac cycle, like the intra-aortic balloon pump and earlier models of the external counterpulsation. Afterward, many studies were conducted to asses this noninvasive method of treatment in patients with CAD. Later on, in 1995, the earliest randomized clinical trial study of EECP on patients with stable angina named the Multicenter Study of Enhanced External Counterpulsation was conducted. The result was a significant decrease in angina attacks and an increase in exercise tolerance among patients treated with EECP. ${ }^{31}$ It has been shown that EECP can improve symptoms of angina and expand tolerance in exercise among patients with symptomatic CAD. The decrease in anginal attacks and nitrates consumption and enhancement in cardiac function are other outcomes after EECP treatment courses. ${ }^{31,32}$ Studies have also proposed that improvement in anginal symptoms of patients under EECP treatment and persistence of the outcomes may be due to the effects on the peripheral vessels in addition to its conventional effects on acute hemodynamic statues. ${ }^{33}$

It has been also shown that EECP can improve other diseases such as restless legs syndrome, retinal artery occlusion, and kidney excretory function..$^{34-36}$

As mentioned above, there are several conditions related to circulatory compromise where EECP can play a beneficial role. However, additional studies are necessary in this area. ${ }^{37}$

\section{Mechanism of action and technique of EECP}

Many hemodynamic results can be seen in patients under EECP treatment. Some of the mechanisms accounting for both cardiac and peripheral effects are as follows.

EECP reduces cardiac demand via reduction in afterload and also helps the collateralization of myocardium through arteriogenesis and angiogenesis. ${ }^{38}$ There is also increased endothelial function and vasodilation through diastolic aug- 
mentation of blood flow and endothelial shear stress, which may result in increased levels of prostacyclin, nitric oxide, vascular endothelial growth factor, and $\beta$ fibroblast growth factor and a reduction in endothelin- 1 and brain natriuretic peptide concentrations..$^{39,40}$

EECP increases blood flow, not only to the heart but also throughout the body; for example, an $88 \%$ increase in infra-renal abdominal aorta, a 144\% surge in internal iliac blood flow, and a significant increase in the perfusion of the brain were reported by Werner et al, ${ }^{41}$ Also, it can possibly enhance penile arterial vasodilation and improve erection by increasing nitric oxide production. ${ }^{11,29}$

EECP therapy structure includes three groups of pneumatic cuffs attached to the calves, lower and upper thighs. ${ }^{38}$ Inflation of the cuffs is triggered consecutively at the beginning of diastole resulting in a diastolic rise of blood flow, increase in venous return, cardiac output, and coronary bloodstream. At the termination of diastole, the cuff is deflated, leading to a decrease in vascular resistance, left ventricular unloading, and growing cardiac output. ${ }^{11}$

There are no conclusive evidence-based indications for EECP usage in different groups of patients; however, some studies have shown the benefits of this modality. A typical course of therapy for EECP is usually set for 1 hour in a day, 5 days a week, and overall, 35 hours. The therapeutic course can be extended for patients who have not experienced improvement in their symptoms; so extra treatment may be considered for the patients to reach individual treatment goals. In about $20 \%$ of the patients, a repeat EECP may be needed, especially for those who failed to complete the initial 35 hours of EECP course of therapy. ${ }^{42}$

EECP treatment courses are contraindicated among special groups of patients such as those with arrhythmias (which affects machine triggering), decompensated heart failure, uncontrolled hypertension (>180/110 $\mathrm{mmHg}$ ), severe pulmonary hypertension (pulmonary artery mean $>50 \mathrm{mmHg}$ ), severe aortic regurgitation, claudication due to severe lower limb vascular disorder or ischemic ulcers without healing, aortic aneurysm necessitating invasive intervention, lower limb thrombophlebitis (within 2 months), lower limb deep venous thrombosis, hemorrhagic diathesis, under warfarin treatment with international normalized ratio $\geq 3.0$, and pregnant patients. ${ }^{43}$

\section{Objectives}

The objective was to review the clinical effectiveness of EECP for patients with ED.

\section{Search methods}

From inception up to September 12, 2017, PubMed, MEDLINE, Google Scholar, Tripdatabase, Scopus, and Cochrane library databases were searched for articles with the following search terms: Enhanced external counterpulsation and Erectile dysfunction.

We did not impose any restrictions with respect to study setting, date of publication, or language.

\section{Selection criteria}

We included all types of clinical studies addressing both EECP and ED except publication types that were conference presentations or letter to editors.

\section{Data extraction}

The algorithm of article selection is provided in Figure 1.

We identified $n=208$ records in which $n=22$ were duplicates. All reviews $n=175$ were excluded, as well as records that did not address EECP, EECP studies only on cardiac disease, and those that were not matched with the selection criteria. Furthermore, all EECP studies that had not addressed ED treatment were excluded $(n=7)$. From a primary set of 208 records, four studies were finally included in this review.

\section{Results}

All studies included in this qualitative review are listed in Table 1.

In 1998, Froschermaier et $\mathrm{al}^{29}$ published the initial trial of EECP in patients with ED in a before and after study design. They treated 13 patients aged between 43 and 68 years old (mean 57.85 \pm 6.32 years) with EECP 1 hour per day for 5 days a week over 4 weeks with a mean follow-up time of $11 \pm 7.35$ months. Participants were evaluated by Doppler ultrasound of the cavernosal arteries after the application of the intracavernous prostaglandin $\mathrm{E}$ (PGE) and also answering a questionnaire before and after the completion of the EECP treatment regimen. This questionnaire contains four questions, where the higher scores indicate better quality of the erection.

Within 1 week after the final course of EECP, there was an $87.5 \%$ increase in the peak systolic flow $(P=0.017)$ and a significant improvement in the penile resistance index $(13.5 \%, P<0.008)$ and in the quality of erection $(58.2 \%$, $P<0.003)$ after administration of $5 \mu \mathrm{g}$ of PGE.

After 1 month of EECP modality course completion, the participants answered the questionnaire for the second time, in which 5 of the 13 participants $(38.5 \%)$ had a significant subjective enhancement in penile rigidity based on which 

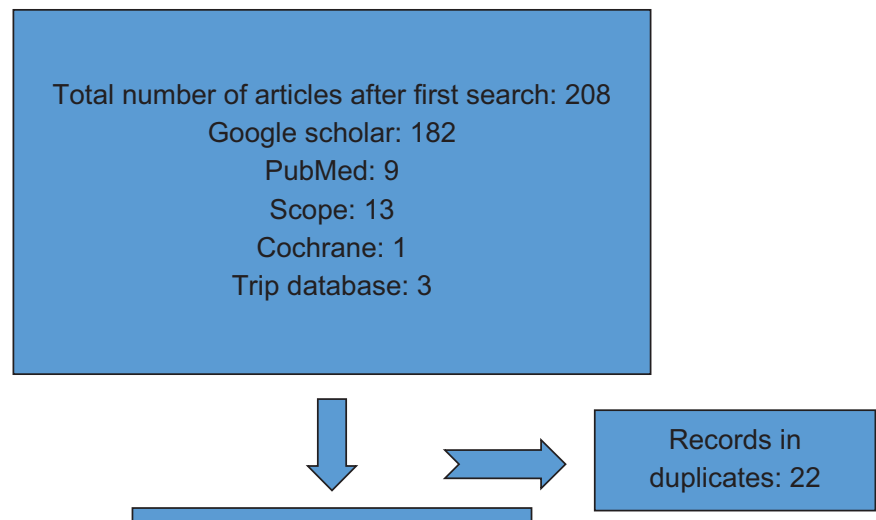

Records screened by

title and abstract: 186

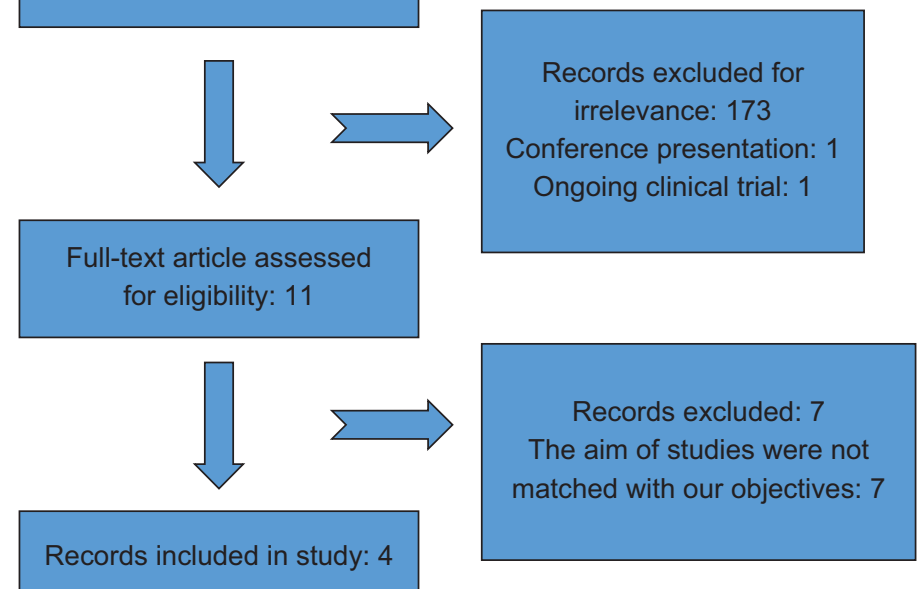

Figure I Flow diagram of the study selection process.

acceptable sexual intercourse (SI) was probable. Moreover, six patients $(46.1 \%)$ reported an improvement of penile rigidity and satisfactory SI more often than before EECP. In two patients (15.4\%), penile rigidity continued unaffected. Finally, 8 out of 10 patients stated spontaneous morning erections, formerly absent, after treatment.

The mean period of improvement in the 11 responders was $6.7 \pm 4.37$ months with no reported side effects; therefore, it was concluded that EECP is effective in patients with ED.

In 2007, Lawson et al $^{11}$ evaluated the outcome of EECP on sexual function in patients with severe refractory angina in a substudy, using the patients enrolled in the International Enhanced External Counterpulsation Patient Registry 2 study.

They implemented EECP treatment on 120 males with

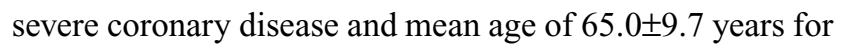
1 hour per day, 5 days per week, and overall, 35 hours.

The questionnaire of the International Index of Erectile Function (IIEF), which identifies five domains of male sexual function (erectile function, orgasmic function, sexual desire, intercourse satisfaction, and overall satisfaction), was used to evaluate ED pre and post completing a course of EECP.
After 35 hours of EECP application, angina and functional status were improved by $89 \%$ and $63 \%$, respectively.

An assessment of the IIEF scores before and after EECP treatment established significant enhancement in three domains of erectile function (from 10 to $11.8, P=0.003$ ), intercourse satisfaction (from 4.2 to $5, P=0.009$ ), and overall satisfaction (from 4.7 to $5.2, P=0.001$ ). Although the improvements in the scores of orgasmic function and sexual desire were 0.4 and 0.2 , respectively, the difference was not statistically significant. The total score increased from 28 to 31 with the $P$-value of 0.01 .

According to the IIEF total score and the categorization of ED severity into none, mild, moderate, and severe, the comparison of the severity of ED before and after EECP revealed $7.5 \%$ rise in the proportion of participants with no complaint of ED (from $17.5 \%$ to $25 \%$ ) and a $7.5 \%$ decrease in the quantity of patients suffering from severe ED (from $65 \%$ to $57.5 \%$ ).

In contrast to the previous studies, the number of patients recording spontaneous morning erections did not change significantly after the treatment. 
Table I Clinical studies on effects of EECP in patients with ED

\begin{tabular}{|c|c|c|c|c|}
\hline Study & Year & $\mathbf{N}$ & $\begin{array}{l}\text { Treatment duration } \\
\text { (hours) }\end{array}$ & Main findings \\
\hline $\begin{array}{l}\text { Froschermaier } \\
\text { et } \mathrm{al}^{29}\end{array}$ & 1998 & 13 & 20 hours & $\begin{array}{l}\text { - An } 87.5 \% \text { increase in the peak systolic flow }(P=0.017) \\
\text { - A } 13.5 \% \text { increase in the penile resistance index }(P<0.008) \\
\text { - A } 58.2 \% \text { increase in the quality of erection }(P<0.003) \text { assessed by } \\
\text { a four-item questionnaire } \\
\text { - An } 84.6 \% \text { of patients had improvement in ED with } 38.5 \% \text { showing } \\
\text { complete resolution after EECP }\end{array}$ \\
\hline Lawson et al" & 2007 & 120 & 35 hours & $\begin{array}{l}\text { The post EECP erectile function domain score of the IIEF } \\
\text { questionnaire improved from } 10.0 \text { to II } 1.8(P=0.003) \text {. Intercourse } \\
\text { satisfaction domain score increased from } 4.2 \text { to } 5.0(P=0.009) \\
\text { and overall satisfaction domain score improved from } 4.7 \text { to } 5.2 \\
(P=0.00 I) \text { with no significant change in orgasmic function or } \\
\text { sexual desire domain scores } \\
\text { - The total score of IIEF increased from } 28 \text { to } 3 \mathrm{I}(P=0.0 \mathrm{I}) \text { after } \\
\text { EECP }\end{array}$ \\
\hline El-Sakka et al $^{44}$ & 2007 & 44 & 35 hours & $\begin{array}{l}\text { - An overall satisfaction of } 79.5 \% \text { of patients about both anginal and } \\
\text { erectile function improvement before and after EECP assessed by } \\
\text { two separate questions } \\
\text { - A significant difference in the erectile function domain, Q3, and } \\
\text { Q4 of IIEF questionnaire }(P<0.05) \text { pre and post EECP } \\
\text { - The efficacy and satisfaction rate of EECP were negatively } \\
\text { influenced by smoking and the presence of more than two risk } \\
\text { factors }\end{array}$ \\
\hline El-Sakka et al $^{16}$ & 2007 & $\begin{array}{l}44 \\
\text { (The same } \\
\text { patients } \\
\text { of the } \\
\text { previous } \\
\text { study) }\end{array}$ & $\begin{array}{l}35 \text { hours } \\
\text { A similar course was } \\
\text { repeated for patients } \\
\text { with no or minimal } \\
\text { improvement from class } \\
\text { IV to class III angina after } \\
\text { the first course }\end{array}$ & $\begin{array}{l}\text { - EF domain, Q3, and Q4 of IIEF questionnaire answers were } \\
\text { significantly higher before and after EECP in patients with }<5 \\
\text { years duration of IHD than those with } \geq 5 \text { years of duration } \\
\text { - At the end of the first course of treatment, the pre and } \\
\text { post EECP results regarding EF domain, Q3, and Q4 of IIEF } \\
\text { questionnaire were significantly better in patients who received } \\
\text { only one course than those who required a second course of } \\
\text { treatment }\end{array}$ \\
\hline
\end{tabular}

Abbreviations: ED, erectile dysfunction; EECP, enhanced external counterpulsation; IHD, ischemic heart disease; IIEF, International Index of Erectile Function.

The authors concluded that EECP remains effective and is related to enhancement in erectile and vascular function in patients with refractory angina.

In 2007, two articles were published by EI-Sakka et al. ${ }^{16,44}$ In the first prospective study, which lacked a control group, the role of risk factors on the effectiveness and satisfaction rate of EECP was studied on 44 men with CAD accompanying ED. ${ }^{44}$ Patients were aged between 46 and 67 years old with the mean age of $57.1 \pm 5.6$ years and underwent a treatment course with EECP for 1 hour per day, 5 days per week, for a total of 35 hours.

ED assessment and follow-up were performed using only the erectile function domain of the IIEF questionnaire. CAD risk factors, for example, dyslipidemia, systemic hypertension, and diabetes mellitus, were also evaluated at the same time as ED screening.

To evaluate the result of risk factors and comorbidities on EECP effectiveness and satisfaction rate before and after the EECP, answers to erectile function domain and also questions Q3 (achieving erection) and Q4 (maintaining erection) of the
IIEF questionnaire were compared separately in participants with and without risk factors. The global efficacy question (GEQ) and overall patient satisfaction question were also evaluated.

The results revealed an overall $79.5 \%$ satisfaction of patients regarding both angina and erectile function improvement after EECP treatment course. A significant difference in the erectile function domain, Q3, and Q4 $(P<0.05)$ were found before and after EECP. Authors also disclosed that the effectiveness and satisfaction rate of this modality were adversely affected by cigarette smoking and presence of more than two risk factors; however, diabetes mellitus, systemic hypertension, dyslipidemia, myocardial infarction, and obesity had no such effects.

In the second part of the study, ${ }^{16}$ which was published in September 2007, the impact of IHD duration and number of EECP treatment courses were assessed in patients with CAD-associated ED. The population size, age, and outcome measurers were the same as in the previous study ${ }^{44}$ Participants received a therapeutic course of EECP for 1 hour per day, 5 
days per week for a total of 35 hours. A similar course was repeated for patients with no or slight progression from class IV to class III angina after the first course of treatment. The patient's before and after EECP responses to the EF domain of IIEF questionnaire, Q3, Q4, GEQ, and overall patient satisfaction question were compared in the two groups of single and two EECP treatment courses. Also, the same variables were compared in the two groups: patients with $<5$ years duration of IHD and those with $\geq 5$ years of disease duration. At the end of the first course of treatment, the pre and post EECP results were significantly higher in patients who finished only one course compared with those who needed an additional course of treatment. Such a significant difference was not seen in the two groups after the completion of the second course of EECP. Furthermore, EF domain and Q3 and Q4 answers were significantly higher before and after EECP in patients with $<5$ years duration of IHD than those with $\geq 5$ years of disease duration.

\section{Conclusion}

According to the extensive and well-known effects of EECP on the arterial tree, which provides an increase in perfusion of all internal organs, there are many utilities for EECP, not only for $\mathrm{CAD}$ and angina but also for other conditions resulting from disturbed organ perfusion and vascular dysfunction such as ED.

To the best of our knowledge, this is the first literature review on the clinical effectiveness of EECP in patients with ED. According to the articles mentioned in this study, an enhancement in erectile function after EECP treatment courses has been observed both in patients with and without CAD without any significant adverse effects. Therefore, EECP could be held in reserve for patients who do not respond to other treatments such as VEDs, oral PDE inhibitors, and intracavernosal injection therapy or for patients who cannot use these modalities due to their comorbidities. However, none of the studies had long-term follow-up data and also a control arm to rule out the risk of the placebo effect of the EECP device or other confounding factors. The small number of patients is another limitation in the three studies mentioned in this review.

It has to be noted that although a statistically significant change in IIEF score was seen with EECP treatment, the changes were very small and may not have been clinically significant.

Since the efficacy and safety of EECP are recognized in noncontrolled studies, there is a need for well-designed randomized clinical trial studies with larger sample sizes and long-term follow-up periods to evaluate this new and noninvasive therapeutic option in patients suffering from ED by excluding the confounders.

\section{Ethical approval}

This study does not contain any articles with human participants or animals written by any of the authors.

\section{Acknowledgments}

We thank our colleague Dr Hamzeh Mazaherylaghab from Hamedan University of Medical Sciences, Department of English, for his assistance. The abstract of this paper was presented at the 12th World Congress of the International Society of Physical and Rehabilitation Medicine (ISPRM 2018). The abstract poster was published in "Poster Abstracts" in Annals of Physical and Rehabilitation Medicine: Volume 61, Supplement, July 2018, Page e389. https://doi.org/10.1016/j. rehab.2018.05.906.

\section{Disclosure}

The authors report no conflicts of interest in this work.

\section{References}

1. NIH Consensus Conference. Impotence. NIH Consensus Development Panel on Impotence. JAMA. 1993;270(1):83-90.

2. Braun M, Wassmer G, Klotz T, Reifenrath B, Mathers M, Engelmann U. Epidemiology of erectile dysfunction: results of the 'Cologne Male Survey'. Int J Impot Res. 2000;12(6):305-311.

3. Feldman HA, Goldstein I, Hatzichristou DG, Krane RJ, McKinlay JB. Impotence and its medical and psychosocial correlates: results of the Massachusetts Male Aging Study. J Urol. 1994;151(1):54-61.

4. El-Sakka AI. Erectile dysfunction in Arab countries. Part I: prevalence and correlates. Arab J Urol. 2012;10(2):97-103.

5. Ramezani MA, Ahmadi K, Ghaemmaghami A, Marzabadi EA, Pardakhti F. Epidemiology of sexual dysfunction in Iran: a systematic review and meta-analysis. Int J Prev Med. 2015;6:43.

6. McKinlay JB. The worldwide prevalence and epidemiology of erectile dysfunction. Int J Impot Res. 2000;12(Suppl 4):S6-S11.

7. Ayta IA, McKinlay JB, Krane RJ. The likely worldwide increase in erectile dysfunction between 1995 and 2025 and some possible policy consequences. BJU Int. 1999;84(1):50-56.

8. Jønler M, Moon T, Brannan W, Stone NN, Heisey D, Bruskewitz RC. The effect of age, ethnicity and geographical location on impotence and quality of life. Br J Urol. 1995;75(5):651-655.

9. Ventegodt S. Sex and the quality of life in Denmark. Arch Sex Behav. 1998;27(3):295-307.

10. Diokno AC, Brown MB, Herzog AR. Sexual function in the elderly. Arch Intern Med. 1990;150(1):197-200.

11. Lawson WE, Hui JC, Kennard ED, et al; IEPR Investigators. Effect of enhanced external counterpulsation on medically refractory angina patients with erectile dysfunction. Int J Clin Pract. 2007;61(5):757-762.

12. Greenstein A, Chen J, Miller H, Matzkin H, Villa Y, Braf Z. Does severity of ischemic coronary disease correlate with erectile function? Int $J$ Impot Res. 1997;9(3):123-126.

13. Montorsi F, Briganti A, Salonia A, et al. Erectile dysfunction prevalence, time of onset and association with risk factors in 300 consecutive patients with acute chest pain and angiographically documented coronary artery disease. Eur Urol. 2003;44(3):360-364; discussion 364- 365.

14. Montorsi P, Montorsi F, Schulman CC. Is erectile dysfunction the "tip of the iceberg" of a systemic vascular disorder? Eur Urol. 2003;44(3):352-354.

15. Solomon H, Man JW, Wierzbicki AS, Jackson G. Relation of erectile dysfunction to angiographic coronary artery disease. Am J Cardiol. 2003;91(2):230-231. 
16. El-Sakka AI, Morsy AM, Fagih BI. Enhanced external counterpulsation in patients with coronary artery disease-associated erectile dysfunction. Part II: impact of disease duration and treatment courses. J Sex Med. 2007;4(5):1448-1453.

17. Chiurlia E, D'Amico R, Ratti C, Granata AR, Romagnoli R, Modena MG. Subclinical coronary artery atherosclerosis in patients with erectile dysfunction. J Am Coll Cardiol. 2005;46(8):1503-1506.

18. Kawanishi Y, Lee KS, Kimura K, et al. Screening of ischemic heart disease with cavernous artery blood flow in erectile dysfunctional patients. Int J Impot Res. 2001;13(2):100-103.

19. Heruti RJ, Uri I, Arbel Y, Swartzon M, Galor S, Justo D. Erectile dysfunction severity might be associated with poor cardiovascular prognosis in diabetic men. $J$ Sex Med. 2007;4(2):465-471.

20. Mulligan T, Katz PG. Erectile failure in the aged: evaluation and treatment. J Am Geriatr Soc. 1988;36(1):54-62.

21. El-Sakka AI. Association of risk factors and medical comorbidities with male sexual dysfunctions. J Sex Med. 2007;4(6):1691-1700.

22. Salavati A, Mehrsai A, Allameh F, et al. Is serum uric acid level correlated with erectile dysfunction in coronary artery disease patients? Acta Med Iran. 2016;54(3):173-175.

23. Jackson G, Boon N, Eardley I, et al. Erectile dysfunction and coronary artery disease prediction: evidence-based guidance and consensus. Int J Clin Pract. 2010;64(7):848-857.

24. Montague DK, Barada JH, Belker AM, et al. Clinical guidelines panel on erectile dysfunction: summary report on the treatment of organic erectile dysfunction. The American Urological Association. J Urol. 1996;156(6):2007-2011.

25. Hatzimouratidis K, Hatzichristou DG. A comparative review of the options for treatment of erectile dysfunction: which treatment for which patient? Drugs. 2005;65(12):1621-1650.

26. Linet OI, Ogrinc FG. Efficacy and safety of intracavernosal alprostadil in men with erectile dysfunction. The Alprostadil Study Group. NEngl J Med. 1996;334(14):873-877.

27. Lewis RW, Witherington R. External vacuum therapy for erectile dysfunction: use and results. World J Urol. 1997;15(1):78-82.

28. Govier FE, Gibbons RP, Correa RJ, Pritchett TR, Kramer-Levien D. Mechanical reliability, surgical complications, and patient and partner satisfaction of the modern three-piece inflatable penile prosthesis. Urology. 1998;52(2):282-286.

29. Froschermaier SE, Werner D, Leike S, et al. Enhanced external counterpulsation as a new treatment modality for patients with erectile dysfunction. Urol Int. 1998;61(3):168-171.

30. Zheng ZS, Li TM, Kambic H, et al. Sequential external counterpulsation (SECP) in China. Trans Am Soc Artif Intern Organs. 1983;29: 599-603.
31. Arora RR, Chou TM, Jain D, et al. The multicenter study of enhanced external counterpulsation (MUST-EECP): effect of EECP on exerciseinduced myocardial ischemia and anginal episodes. J Am Coll Cardiol. 1999;33(7):1833-1840.

32. Urano H, Ikeda H, Ueno T, Matsumoto T, Murohara T, Imaizumi T. Enhanced external counterpulsation improves exercise tolerance, reduces exercise-induced myocardial ischemia and improves left ventricular diastolic filling in patients with coronary artery disease. $\mathrm{J} \mathrm{Am}$ Coll Cardiol. 2001;37(1):93-99.

33. Yang DY, Wu GF. Vasculoprotective properties of enhanced external counterpulsation for coronary artery disease: beyond the hemodynamics. Int J Cardiol. 2013;166(1):38-43.

34. Werner D, Trägner P, Wawer A, Porst H, Daniel WG, Gross P. Enhanced external counterpulsation: a new technique to augment renal function in liver cirrhosis. Nephrol Dial Transplant. 2005;20(5):920-926.

35. Rajaram SS, Shanahan J, Ash C, Walters AS, Weisfogel G. Enhanced external counter pulsation (EECP) as a novel treatment for restless legs syndrome (RLS): a preliminary test of the vascular neurologic hypothesis for RLS. Sleep Med. 2005;6(2):101-106.

36. Werner D, Michalk F, Harazny J, Hugo C, Daniel WG, Michelson G. Accelerated reperfusion of poorly perfused retinal areas in central retinal artery occlusion and branch retinal artery occlusion after a short treatment with enhanced external counterpulsation. Retina. 2004;24(4):541-547.

37. Braverman DL. Enhanced external counterpulsation: an innovative physical therapy for refractory angina. PM R. 2009;1(3):268-276.

38. Manchanda A, Soran O. Enhanced external counterpulsation and future directions: step beyond medical management for patients with angina and heart failure. J Am Coll Cardiol. 2007;50(16):1523-1531.

39. Niebauer J, Cooke JP. Cardiovascular effects of exercise: role of endothelial shear stress. J Am Coll Cardiol. 1996;28(7):1652-1660.

40. Garlichs CD, Zhang H, Werner D. Reduction in serum endothelin-1 levels by pneumatic external compression [abstract]. Can J Cardiol. 1998; $14: 87 \mathrm{~F}$.

41. Werner D, Schneider M, Weise M, Nonnast-Daniel B, Daniel WG. Pneumatic external counterpulsation: a new noninvasive method to improve organ perfusion. Am J Cardiol. 1999;84(8):950-952.

42. Sharma U, Ramsey HK, Tak T. The role of enhanced external counter pulsation therapy in clinical practice. Clin Med Res. 2013;11(4):226-232.

43. Michaels AD, McCullough PA, Soran OZ, et al. Primer: practical approach to the selection of patients for and application of EECP. Nat Clin Pract Cardiovasc Med. 2006;3(11):623-632.

44. El-Sakka A, Morsy A, Fagih B. Enhanced external counterpulsation in patients with coronary artery disease-associated erectile dysfunction. Part I: effects of risk factors. J Sex Med. 2007;4(3):771-779.
Vascular Health and Risk Management

\section{Publish your work in this journal}

Vascular Health and Risk Management is an international, peerreviewed journal of therapeutics and risk management, focusing on concise rapid reporting of clinical studies on the processes involved in the maintenance of vascular health; the monitoring, prevention and treatment of vascular disease and its sequelae; and the involvement of metabolic disorders, particularly diabetes. This journal is indexed on PubMed Central and MedLine. The manuscript management system is completely online and includes a very quick and fair peer-review system, which is all easy to use. Visit http://www.dovepress.com/ testimonials.php to read real quotes from published authors. 